\title{
Effect of the Morphology of Electrospun Polyvinylidene Fluoride Nanofiber on Corrosion Property of Q345 Steel
}

\author{
Yuhua Dong ${ }^{*}$, Siyi Li, Qiong Zhou \\ College of Science, China University of Petroleum (Beijing), Beijing 102249, China \\ *E-mail: dyhydt@yahoo.com
}

doi; $10.20964 / 2017.12 .73$

Received: 26 May 2017 / Accepted: 28 September 2017 / Published: 12 November 2017

Different contents of polyvinylidene fluoride (PVDF) nanofiber membranes were electrospun on Q345 steel surface. Nanofiber morphology was observed via scanning electron microscopy. The samples were immersed in $3.5 \mathrm{wt}$. \% solutions, and an electrochemical workstation was used to investigate the anticorrosion performance of the nanofiber membranes. Electrochemical impedance spectroscopy measurements indicated that the electrospun PVDF nanofiber membranes effectively protected the Q345 steel. Nanofiber morphology significantly influenced its protection property. The nanofiber membranes with uniform thickness exhibited better performance than the membranes with a beaded structure. The nanofiber membrane included in the epoxy resin composite coating improved protection performance of the coating.

Keywords: Electrospun; Nanofiber membrane; EIS; Corrosion

\section{$\underline{\text { FULL TEXT }}$}

(C) 2017 The Authors. Published by ESG (www.electrochemsci.org). This article is an open access article distributed under the terms and conditions of the Creative Commons Attribution license (http://creativecommons.org/licenses/by/4.0/). 